\title{
Factive vs. Ideological Knowledge in Political Discourse
}

\author{
Thouraya Zheni ${ }^{1}$ \\ ${ }^{1}$ English Language Centre, Deanery of Academic Services, Taibah University, Madina, KSA \\ Correspondence: Thouraya Zheni, Preparatory Year Building, Madina Female Campus, Taibah University, \\ Madina, KSA. E-mail: thouraya_zheni@hotmail.fr or zhenithouraya80@gmail.com
}

Received: August 11, 2018 Accepted: November 29, 2018 Online Published: December 27, 2018

doi:10.5539/ijel.v9n1p36 URL: https://doi.org/10.5539/ijel.v9n1p36

\begin{abstract}
Since political discourse portrays politicians' knowledge state and their ideological assumptions, a critical analysis of Clinton's speeches may unveil her perceptual and conceptual worlds. More specifically, CDA may uncover Clinton's mental representations about the Tunisian Revolution and the US attitude towards such an important political event in North Africa and the Middle East. Studying factive presupposition and epistemic modality seems to be an effective pragmatic tool to reveal what is presented as factual or ideological knowledge in political discourse. The research instrument used to sort out the frequency distribution of lexical features, mainly factive and emotive verbs, factive noun phrases, mental state verbs and epistemic modal adjectives and adverbs, is the latest version of "AntConc" software. To uncover the epistemic state of Hillary Clinton, van Dijk's (1995a) approach is implemented to analyze her speeches between January 2011 and December 2012. At the discourse level, research findings reveal that factive presupposition unveils the speaker's strong personal commitment to the truth value of her propositions. At the cognitive level, results show that the speaker's personal and social ideologies and knowledge are demystified by the cognitive mechanisms that govern discourse production and understanding via Idealized Cognitive Models (ICMs), cognitive frames and mental models. This study bridges the gap caused by the lack of research on factive vs. ideological knowledge in political discourse from a socio-cognitive perspective.
\end{abstract}

Keywords: factive vs. ideological knowledge, mental models, van Dijk's cognitive approach, Idealized Cognitive Models, political discourse

\section{Introduction}

\subsection{Research Problem}

The current research has been prompted by the proposition that Hillary Clinton's implicit, hidden, or covered ideological assumptions are presented in her utterances as factive, indisputable knowledge. Clinton's mental models may be ideology-laden assumptions that locate democratic and non-democratic communities in certain mental frames. Consequently, factive presupposition and epistemic modality have been selected to be analyzed within the framework of CDA, particularly van Dijk's (1995a) discourse-cognition-society triangular approach. The aim is uncovering factive, presupposed knowledge of the speaker as well as the ideological, exposed knowledge relating to human rights and democracy in Hillary Clinton's discourse on Tunisia's democratic transition. The present paper examines both knowledge and ideology from a socio-cognitive approach. It sheds light on the difference between the two concepts and their relationships with discourse.

\subsection{Research Questions}

1) What lexical features does Hillary Clinton use to express knowledge in her discourse?

2) What kind of ideological traces can the analyst find in her political discourse?

3) How is knowledge manifested cognitively in Clinton's political discourse?

4) Are the propositional contents of the speaker's utterances presented as factive knowledge or ideological assumptions? 


\section{Literature Review}

\subsection{Knowledge}

Knowledge is defined in various ways. Knowledge refers to "the consensual beliefs of an epistemic community and shall reserve truth as a property of assertions" (van Dijk, 2003c, p. 85). The truthfulness of such beliefs has no value except if it is asserted in discourse (van Dijk, 2003c, p. 85). Knowledge can, therefore, be defined as justified beliefs shared by an epistemic community and based on the epistemic criteria or standards of the knowledge community, also called "k-community" (van Dijk, 2012, p. 587). Knowledge is relative to this k-community since what accounts as knowledge for one k-community may be evaluated as false beliefs by another community. Knowledge is contextual because justified beliefs in one context may not be justified or asserted in another context. Knowledge is also viewed as a form of social cognition. Indeed, knowledge is not defined as personal beliefs, but as "social beliefs certified, shared and hence discursively presupposed by the members of epistemic communities" (van Dijk, 2005, p. 87). Knowledge is certified as such depending on the knowledge criteria of the competent members of an epistemic community (van Dijk, 2003a, p. 95).

There are two major types of knowledge, mainly personal and social knowledge. Personal knowledge is based on personal mental models or experiences about specific events (van Dijk, 2004a, p. 13). It is private, and thus not shared by others unless it is communicated (van Dijk, 2005, p. 78). Social knowledge, however, stems from general, abstract and socially shared representations. According to Tulving (1983), as cited in van Dijk (2005, p. 74), social knowledge is represented in semantic or social memory, while personal knowledge about specific events is stored as mental models in episodic memory. Social knowledge is itself divided into interpersonal, group and institutional knowledge. First, interpersonal knowledge can be defined as the personal knowledge shared by two or more people and communicated in previous interpersonal, common experiences (van Dijk, 2005 , p. 78). Second, group knowledge is "the socially shared knowledge, either of group experiences or of general, abstract knowledge acquired by the members of a group, such as a professional group, a social movement or a sect" (van Dijk, 2005, p. 78). Third, institutional or organizational knowledge is the socially shared knowledge by the members of an organization or institution (van Dijk, 2005, p. 79). Such knowledge may be presupposed by the competent members who acquired it in the socialization process.

In addition, social knowledge is divided into national, cultural and universal knowledge. First, national knowledge is the knowledge shared by the citizens of a country. It is learned at school, via mass media and presupposed in all public discourses by all citizens in that country (van Dijk, 2005, p. 79). Second, cultural knowledge is a general knowledge shared and presupposed by the members of a culture. People identify themselves with a culture on the basis of language, religion, history, habits, origin or appearance. Cultural knowledge is presupposed in the discourses of competent cultural members. Hence, it represents the basic Common Ground for all other discourses and for all other kinds of knowledge (van Dijk, 2005, p. 80). Third, universal knowledge is shared by the international community or presupposed by the competent members of all cultures (van Dijk, 2003c, p. 90).

According to van Dijk and Kintsch (1983), knowledge can also be categorized as episodic and conceptual, or semantic (as cited in Beaugrande, 1991, p. 272). Beaugrande (1991) points out that the first is "construed or inferred from previous experience, [whereas the second is] derived through abstraction, generalization, de-contextualization and recombination" (p. 272). In other words, episodic knowledge consists of saved and stored memories or schemas about past experiences with the real world. Conceptual knowledge, however, stems from the abstract, conceptual world and is, therefore, general, stable and useful for many cognitive tasks (Beaugrande, 1991). In sum, the type of knowledge depends on who shares it, and whether it is presupposed by a small number of people, a group, a culture, or all members of all cultures worldwide (van Dijk, 2003c, p. 90). Tackling knowledge from a socio-cognitive perspective seems to be necessary at this level due to its importance to conducting the present research.

\subsection{Socio-cognitive Approach to Knowledge}

Knowledge is mainly accounted for in cognitive science and more specifically in cognitive and social psychology (van Dijk, 2003b, p. 22). Knowledge has to be examined in a multidisciplinary framework within which cultural, social, cognitive as well as discursive dimensions have to be studied and made explicit. A cognitive account of knowledge processes and structures is, therefore, needed. A social account of the ways knowledge is used and communicated by groups and cultures is also primordial. More specifically, a discursive theory of how knowledge is mediated, manifested and reproduced in text and talk is necessary (van Dijk, 2003a, p. 95). 
Knowledge is closely related to cognitive or mental representations. Indeed, since knowledge is a kind of belief, and since beliefs are considered as mental phenomena, knowledge may be analyzed as a mental structure, like representations (van Dijk, 2004a, p.10). In this regard, the cognitive approach to knowledge highlights its mental structure. Psychology and Artificial Intelligence (AI) consider knowledge as mental representations in memory (van Dijk, 2003c, p. 86). Given the fact that knowledge is mandatory for both speakers and hearers, a complex mental model of the knowledge situation of a given communicative event is, thus, needed (van Dijk, 1999, 2004a). This will be elaborated in the following sections of this paper.

Beliefs and knowledge are cognitively conceptualized as mental representations of the situational states of affairs (van Dijk, 2004a, p. 10). Knowledge is represented as a kind of script, frame or similar structure or format in Long-Term Memory (LTM), but partly utilized and applied in Short-Term Memory (STM). Because knowledge is schematically organized in terms of scripts, this facilitates retrieving, activating and applying it. Discourse comprehension and production and other forms of interaction "presuppose the partial activation and "application" of relevant fragments of knowledge" (van Dijk, 2004a, p. 11). Such activated knowledge can be "instantiated" or "specified" in representations of personal experiences and events, and hence mental models stored in episodic memory.

In this context, it is important to note that discourse understanding consists of building mental models in episodic memory, where general knowledge is evoked during mental model construction (van Dijk, 2004a, p. 11). Depending on context, the speaker decides what fragments should be explicitly expressed in discourse and what knowledge should be left partially or wholly implicit (van Dijk, 2004a, p. 12). Consequently, we may need specific mental models to construct general knowledge, and we may need general knowledge to construe and understand specific mental models (van Dijk, 2004b, p. 74).

Knowledge is not only mental but also social. Different social groups share a large amount of socio-cultural knowledge and several truth criteria (van Dijk, 1998, p. 115). This gives the members of different groups a chance to understand, communicate with and convince one another. Based on Clark's (1996) views, van Dijk (2003c) states that common ground, consensus and common sense are some of the many notions that may define the social aspect of knowledge (p. 86). As such, people's knowledge of the world is "essentially a socially dependent cognitive structure" (van Dijk, 1983, p. 191). It is built and used in processes of communication and interaction in social situations.

After defining knowledge, identifying its different types and highlighting its socio-cognitive dimensions, one has to focus on ideology, its conception and its social and cognitive facets.

\subsection{Ideology: Socio-cognitive Dimensions}

The social aspects of ideology can be defined at the macro and micro levels of society. At the macro level, one can refer to groups of social actors, institutions, organizations, societies, states and their relationships (van Dijk, 2000 , p. 31). At the micro level, however, one may focus on social actors, as well as the social interaction between them in a given social situation, or context (van Dijk, 2000, p. 31). Ideologies are, therefore, defined in terms of social groups, group relations, institutions at the macro level, and in terms of social practices at the micro level (van Dijk, 1998, 2000, 2009). More specifically, ideologies are the basis for the social practices of group members.

As for the cognitive aspects, ideologies are the interface between the cognitive representations and society (van Dijk, 1995a, p. 18). Indeed, ideologies are presented as "basic frameworks of social cognition, shared by members of social groups, constituted by relevant selections of socio-cultural values, and organized by an ideological schema that represents the self-definition of a group" (van Dijk, 1995b, p. 248). Apart from their social role of promoting the interests of groups, ideologies play a cognitive role by organizing the social representations, i.e. attitudes and knowledge, of the group. They also organize and determine the text and talk of group members (van Dijk, 1995b, p. 248). Ideology not only forms the essential building blocks of SRs but also identifies the selection principles of group norms and values, as well as the structural organization of SRs (van Dijk, 1990, p. 177).

Ideologies organize social attitudes and structures. Based on Eagly and Chaiken's (1993) thoughts, van Dijk (1995c) points out that ideologies "organize social group attitudes consisting of schematically organized general opinions about relevant social issues, such as abortion, nuclear energy or affirmative action" (p. 138). Each group may choose the social norms and values that achieve its objectives and serve its interests. Such a group may also use these selected values as "building blocks" for its group ideologies (van Dijk, 1995c, p. 138). Depending on the speaker's perspective, her group membership or ethics, ideologies can be evaluated positively 
or negatively (van Dijk, 2006, p. 729). Since ideologies are part of a social struggle, they are relevant in competitions, conflicts, dominance and resistance between groups.

Like cognition and knowledge, ideology is the interface between discourse and society. More specifically, ideologies are the socio-cognitive interface between societal structures of groups, group relations and institutions, on the one hand, and individual thought and discourse, on the other hand. Given this combined cognitive and social approach to ideology, it can be stated that ideologies are built up by biased and subjective social or political values, and structured by group self-schemata. Categories, like identity, goals, norms, positions and resources, play a detrimental role in building a group's ideology (van Dijk, 1995a, p. 32). The link between ideology and discourse has to be studied in the following sub-section.

\subsection{Knowledge vs. Ideology}

The classical distinction between knowledge (épistémé) and belief (doxa) is closely related to the distinction between knowledge and ideology. The debate on the difference between knowledge and ideology has started since Destritt de Tracy coined the concept of ideology in the 19th C (van Dijk, 2004a, p. 15). Unlike ideology, which was described by Marx and Engels as "false consciousness" or wrong misguided beliefs, the scientific aspect of knowledge is enhanced to highlight its factivity or truthfulness (as cited in van Dijk, 1998, p. 108). In epistemology, knowledge is presented as "justified true beliefs" (van Dijk, 1998, p. 109). Knowledge presupposes truth criteria based on justifications or reliable evidence of true knowledge. Ideologies, however, monitor evaluative beliefs, but cannot monitor knowledge (van Dijk, 1998, p. 112).

At the social level, ideologies are defined as socially shared representations by the members of a group. They are "general, abstract and fundamental, and organize other forms of social representations, such as attitudes" (van Dijk, 2004a, p. 15-6). Such ideologies determine people's beliefs about the world and control the way the epistemic community evaluates knowledge. Ideologies, therefore, affect the socially shared group knowledge, like the specific knowledge shared by feminists, linguists and students. These social representations of a group are clearly ideologically biased. Based on Fairclough's (1995) view, van Dijk (2004a) points out that the "socially shared knowledge cannot possibly "escape" its ideological boundedness" (p. 6). Since ideologies are the basis of socially shared representations, it can be stated that our knowledge may be ideologically biased.

A distinction has, therefore, been drawn between knowledge and ideology. Knowledge may be organized depending on the ideological parameters of the group, such as its goals and interests (van Dijk, 2004a, p. 16). In other words, the reality is perceived, interpreted and represented according to that group convenience. Consequently, a distinction must be drawn between the ideology of a group and the knowledge of that group because knowledge may be biased. Such group knowledge may be mere beliefs, or opinions, by the members of the group (van Dijk, 2004a, p. 17). In interactions and discourse, these members present such beliefs as facts and deal with them as knowledge.

Consequently, culturally shared beliefs or ideologies can be taken as factive knowledge. In some groups, knowledge is not always ideological, but widely shared and presupposed in larger epistemic communities, like cultures. So, there are different kinds of beliefs that are considered as the equivalent of facts (van Dijk, 2004a, p. 17). In other words, beliefs function as "the epistemic common ground" of such an epistemic community. These indisputable facts can be part of the approved or accepted knowledge that is shared and presented by ideological opponents or rivals of these communities (van Dijk, 2004a, p. 18). If ideologies determine the social representations of groups, they may also determine the knowledge learned and shared by such groups (van Dijk, 2001, p. 15).

Like ideology, knowledge may be relative depending on the shared beliefs of an epistemic community. In fact, what is presented as knowledge by a group member may be "false beliefs, half-truths, or one-sided true beliefs that favor specific groups, and that are directed against them" (van Dijk, 1998, p. 111). In addition, facts are always constructed, and therefore cognitively and socially relative. They depend on the conceptual and perceptual understanding of people. Language, therefore, "ceases to be a neutral medium of or the transmission and reception of pre-existing knowledge" (Jaworski \& Coupland, 1999, p. 4). Language unveils knowledge that is relative to conceptualizers, circumstances, cultures and ideologies.

To sum up, knowledge and ideology are interrelated, and they influence discourse production and comprehension. Instead of the conventional and epistemological definition of knowledge as justified true beliefs, we need a more sophisticated multidisciplinary theory of knowledge according to different kinds of beliefs typically shared by epistemic communities (van Dijk, 2004a). 


\subsection{Knowledge and Discourse}

A theory of knowledge is incomplete without a theory of discourse. Knowledge is quite essential for the production and comprehension of discourse (van Dijk, 2004a, p. 19). It fundamentally affects many aspects of text and talk (van Dijk, 2003c, p. 98). As such, the previously mentioned kinds of knowledge are manifested and managed in discourse production and processing (van Dijk, 2004a). Much of our knowledge is typically construed and reproduced by discourse. In other words, such knowledge construction is usually mediated via discursive practices. Most of our practical knowledge about the world is built by our personal experiences or acquired from other people via discourse.

The interface between knowledge structures of the mind and discourse processing has to be managed by a knowledge device. Such knowledge device is called "a k-device" or a special element in our context model of the communicative event (van Dijk, 2004a, p. 14). The k-device helps to guess how much knowledge is shared by our recipients, and how much knowledge we need to share or convey. It is constantly active to calculate what the recipients know at each moment of a communicative event or interaction (van Dijk, 2005). It adapts the structure of the text or talk to the dynamically changing common ground of knowledge. For instance, it selects definite or indefinite articles, presupposed that clauses, conversational markers, like "you know", and reminding markers, such as "as I told you yesterday" or "as we reported last week" (van Dijk, 2005, p. 76).

The coordination of the k-context interface is the task of the k-device. People tend to leave the knowledge that we think the recipients share as implicit. This strategy may be floated or violated depending on context. Knowledge can be explicitly mediated in various ways by expressions, like "the fact is", "I am sure that", etc. (van Dijk, 2003a, p. 106). In political discourse, specialized knowledge sources have to be frequently involved so as to legitimate or justify political action or decision, or to support arguments in political discourse (van Dijk, 2003a, p. 110-1). The following is a list of words that presuppose the speaker's knowledge in text or talk:

Table 1. Expressions presupposing the speaker's knowledge (van Dijk, 2003a, p. 112-3)

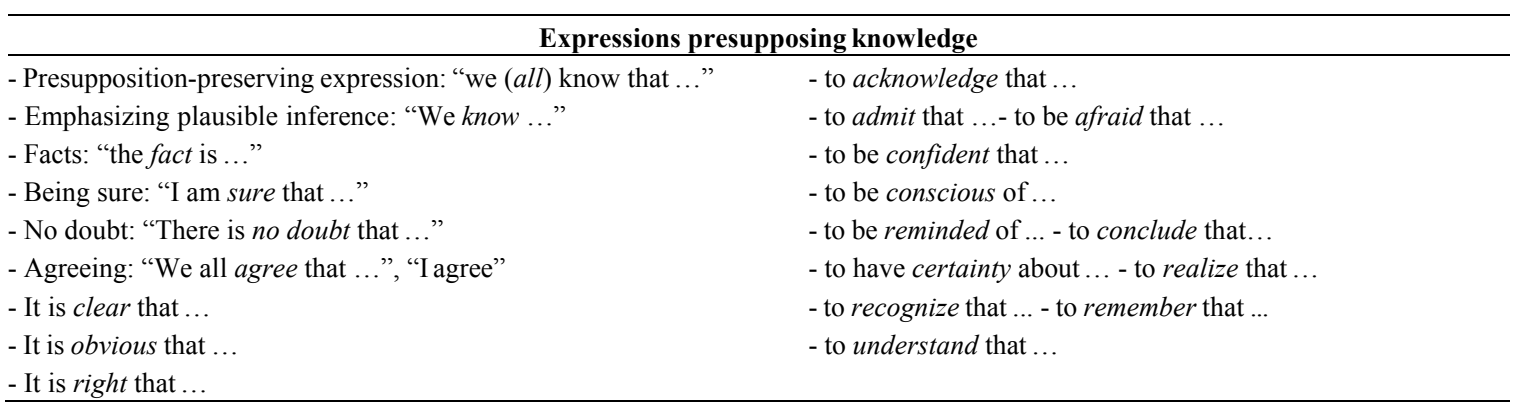

These verbs presuppose knowledge. They may be combined with the expressions in table 2 .

Table 2. Explicit expressions of knowledge and their meaning, adapted from van Dijk (2003a, p. 113)

\begin{tabular}{ll}
\hline Meaning & Expressions \\
\hline - Knowledge of events of the past & (to remember, remind, etc.) \\
- Discovery of (new) knowledge & (to realize) \\
- Certain knowledge & (to be confident that, it is obvious that, it is clear that, ) \\
- Reluctant knowledge & (to be afraid that, fear that, to admit that, to acknowledge that,) \\
- Inferential knowledge & (to conclude that, understand that) \\
\hline
\end{tabular}

The above-mentioned examples reveal that knowledge is about complex and different kinds of mental representations or propositional attitudes that range from mere beliefs to absolute certainty. This depends on the knowledge state of users, context and the strategies of their discursive manifestation. This knowledge may be about "past, present or future, about real, fictitious or abstract events, be old or new knowledge, and acquired by observation, experience, inference or more or less reliable sources" (van Dijk, 2003a, p. 113). In short, knowledge is not one type of belief, but a large field of mental experiences.

However, large amounts of knowledge are not available or expressed by the text. Based on van Dijk and Kintsch (1983), Beaugrande (1991) states that these amounts of knowledge have to be "accessed and retrieved to provide 
a framework for the text, organize it, understand it, and construct a mental representation in memory" (p. 272). Language users, not only need to have general knowledge of the world, or knowledge about the actual communicative event or situation, but also the shared knowledge with the recipient, or the mutual knowledge of both speakers and hearers (van Dijk, 2005, p. 72). This means that interlocutors must successfully manage the common ground knowledge they need in order to be mutually comprehensible.

In this regard, a theory of knowledge management in discourse and interaction is necessary for CDA. Discourse production and comprehension are context-dependent. Discourse processing should be done in terms of mental models of the relevant facets of the communicative event (van Dijk, 2005, p. 72). In short, an explicit theory of discourse necessitates an explicit theory of knowledge.

\section{Research Methodology}

Hillary Clinton's discourse consists of 27 speeches delivered between January 2011 and December 2012. Given the complexity and length of the speeches, the 3.5.0 "AntConc" concordance software has been chosen to analyze the selected corpus. Factivity is to be analyzed within a combined framework. First, the classification of presupposition triggers is based on the works of Karttunen (1973), Levinson (1983), Yule (1996) and van Dijk (2003a). The data, that is subject to computational analysis, involves factive presupposition triggers, namely factive verbs, such as "know", "prove" and "recognize", emotive verbs, like "regret", "amazed" and "be surprised", and factive noun phrases, like "fact", "truth" and "reality". Second, the analysis of epistemic modality is based on the works of Karttunen (1972), Kratzer (1981, 1991), Lyons (1977) and Perkins (1983), focusing on mental state verbs, epistemic adjectives and epistemic adverbs. These factive presupposition triggers and epistemic modals presuppose knowledge.

To analyze the collected data, the "Speech.an.antconc" file has to be processed by the "AntConc" software. Figure 1 is a Key Word In Context (KWIC) frequency list of the mental state verb "think" in a randomly selected sample:

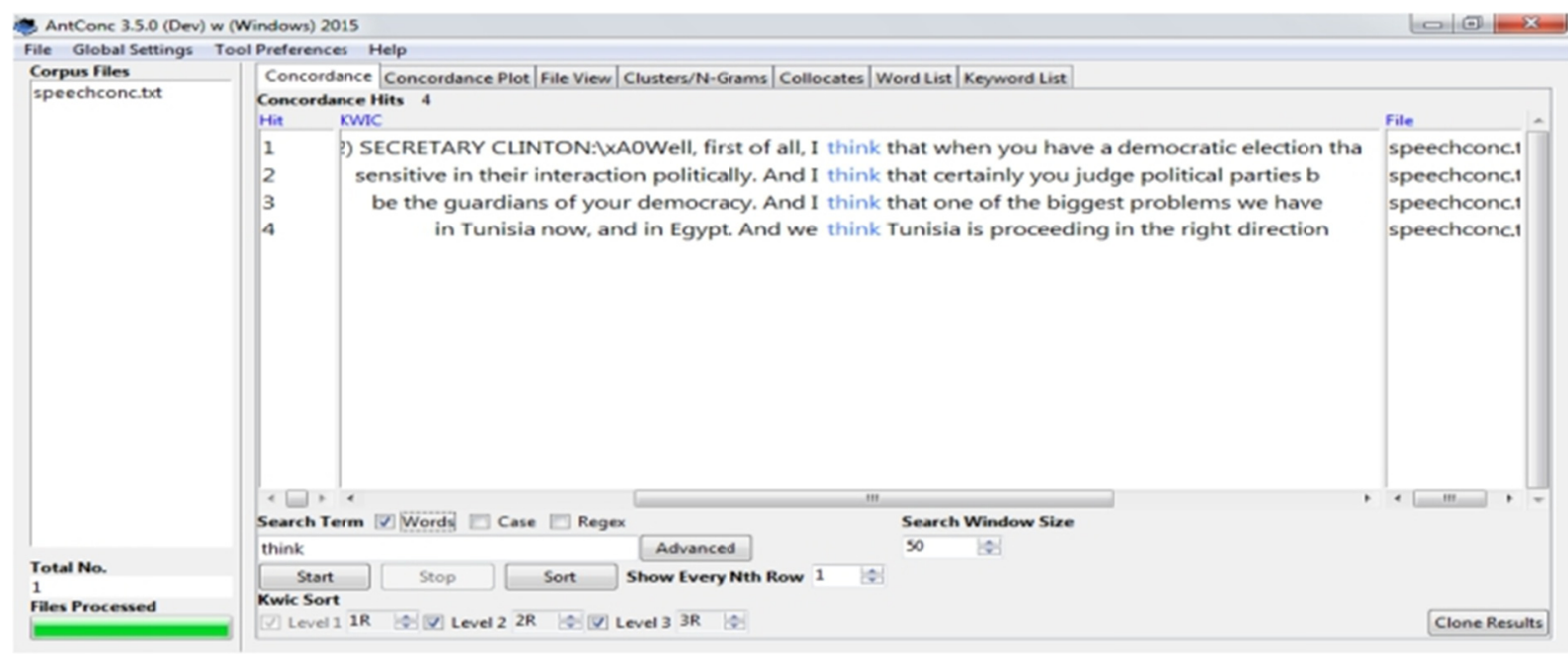

Figure 1. AntCon 3.5.0 screenshot of the frequency distribution of the mental state verb "think" in the sample

KWIC concordance is helpful in that it provides the context in which a presupposition trigger occurs, and therefore, allows the analyst to understand the meaning of epistemic presupposition and distinguish it from other meanings. However, the frequency of occurrence of a presupposition trigger, or the context in which it occurs, cannot allow a deep understanding of the speaker's view of the world, nor can it unveil her social or cognitive representations. This is the aim of the extra-linguistic analysis that goes beyond lexis and semantics to reach pragmatic and cognitive levels. The socio-cognitive analysis of the selected corpus is conducted within van Dijk's (1995a) approach to discourse. Table 3 summarizes the three analytical levels: 
Table 3. Ideologies and discourse: levels of analysis, adapted from van Dijk (1995a, p. 20)

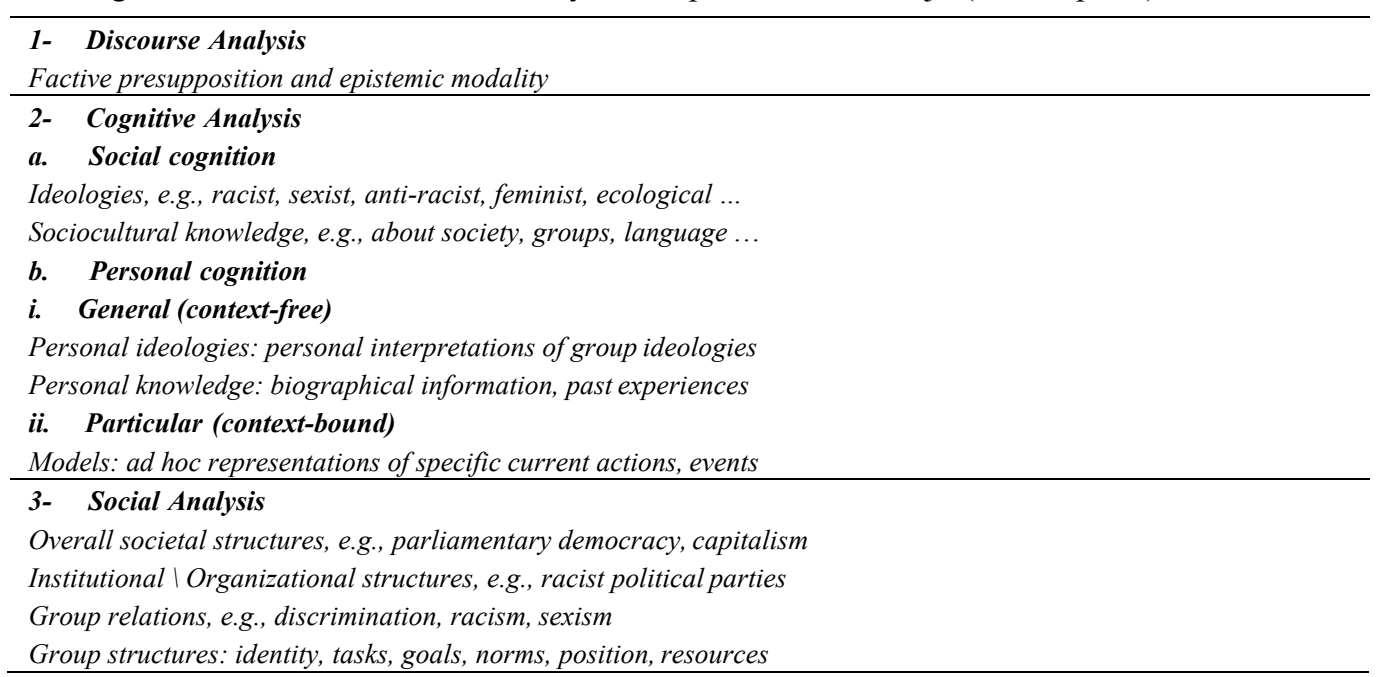

The present research focuses on implementing only the first two stages of analysis of van Dijk's (1995a) approach on Hillary Clinton's political discourse regarding human rights and democracy in the Arab world, more specifically Tunisia in post-Ben Ali era. It aims to demonstrate how ideology-laden knowledge is presented as factive and indisputable in Clinton's discourse.

\section{Results}

This section displays the results obtained from both the computational and manual analyses of the whole corpus. These findings have to be analyzed and interpreted on the basis of two levels of analysis, mainly discourse and cognition.

\subsection{Discursive Analysis}

After the computational and manual analyses of the collected data, the following frequency lists have been obtained:

Table 4. Frequency distribution of factive presupposition triggers and epistemic modals in the corpus (both computational and manual analyses)

\begin{tabular}{|c|c|c|c|}
\hline \multicolumn{2}{|c|}{ Factive lexical triggers (94 items) } & \multirow[b]{2}{*}{$\begin{array}{l}\text { Epistemic modality } \\
(104 \text { items })\end{array}$} & \multirow[b]{2}{*}{$\begin{array}{c}\text { Total } N \text { of } \\
\text { Lexical Items }\end{array}$} \\
\hline $\begin{array}{l}\text { Factive verbs } \\
(80 \text { items })\end{array}$ & $\begin{array}{c}\text { Emotive verbs } \\
\text { (5 items) }\end{array}$ & & \\
\hline Be aware (2) & Be proud (5) & Mental state verbs (62 items) & \multirow{7}{*}{198} \\
\hline $\begin{array}{l}\text { Be forced }(1) \\
\text { Forget }(1)\end{array}$ & & $\begin{array}{l}\text { Acknowledge (1), admit (1), think (51), } \\
\text { understand (9) }\end{array}$ & \\
\hline Know (51) & Factive Noun & Modal adverbs (18 items) & \\
\hline Prove(3) & Phrases & Certainly (10), clearly (3), & \\
\hline Realize(1) Recognize & (9 items) & obviously (4), probably (1) & \\
\hline (15) Remember(4) & Fact $(3)$ & Modal adjectives ( 24 items) & \\
\hline Remind (2) & No doubt (4) Reality (2) & $\begin{array}{l}\text { Certain (1), clear (7), confident } \\
\text { (4), obvious (2), sure (2), true (8) }\end{array}$ & \\
\hline
\end{tabular}

After examining Table 4, which illustrates the lexical features to be analyzed in the whole corpus, one can note the important use of factive presupposition in Clinton's political discourse, with a total number of 94 lexical items. Factive predicates come first with 80 occurrences, followed by factive noun phrases with 9 uses and emotive verbs with 5 uses. The most frequently used item in the category of factive predicates is the verb "know" with 51 occurrences, followed by the verb "recognize" (15 items) and "remember" (4 items). As for the noun phrase category, the noun phrase "no doubt" is used 4 times, while the noun "fact" is repeated 3 times. The noun "reality" occurs only 2 times in the corpus. Finally, only the emotive verb "be proud" is used in the corpus (5 times). 
One can also highlight the important use of epistemic modals (104 occurrences), mainly mental state verbs (62 occurrences), modal adjectives (24 items) and modal adverbs (18 uses). Among the mental state verb category, the verb "think" is the most dominant mental state predicate with 51 items. The second most frequently used verb is "understand" with 9 occurrences. Among the modal adjective category, one can notice the dominance of the adjectives "true" ( 8 features) and "clear" ( 7 features), and the quite important use of the adjective "confident" (4 features). Finally, within the epistemic modal adverb category, one can highlight the important use of the adverb "certainly" (10) and the approximately similar uses of the adverbs "obviously" (4) and "clearly" (3). One can, therefore, note that factive predicates (80) and mental state verbs (62) are the most dominant lexical categories in Clinton's political discourse.

\subsection{Cognitive Analysis}

The present stage of van Dijk's approach (1995a) examines the speaker's personal and social cognitions displayed in discourse, i.e. personal and social ideologies and knowledge. More emphasis has to be on factive vs. ideological knowledge and the mental mappings that may locate Tunisia in certain cognitive frames or mental categories. Similar attention has to be paid to presupposed knowledge, triggered by factive presupposition and epistemic modality, controlled by mental models and built upon the background, ideological knowledge of the U.S. ex-Secretary of State, Hillary Clinton.

\subsubsection{Text-Based Mental Models}

Text-based mental models are manifested in the semantic structures of Hillary Clinton's discourse. Concern has to be about highlighting the mental frames related to the Tunisian revolution, Tunisia's democratic transition and the speaker's mental representations about human rights and democracy in post-revolution Tunisia, or "new Tunisia". After analyzing mental models built in the corpus, one can note that they are organized in hierarchical and categorical structures. Figure 2 illustrates the hierarchical structure of mental models representing human rights and democracy in the corpus:
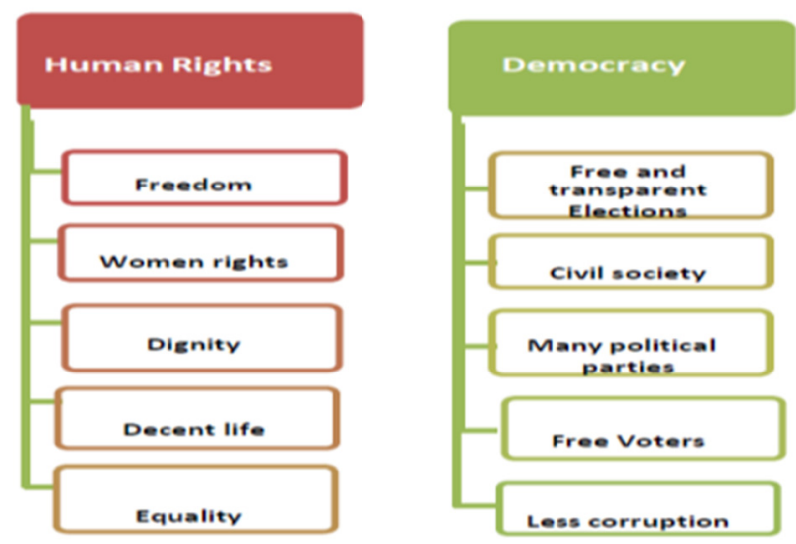

Figure 2. Diagrammatic representation of the organizational structures of human rights and democracy image schemas in Clinton's episodic memory

Figure 2 shows how mental representations are structurally classified into general and specific image schemas. In the selected corpus, one can notice two general mental models, mainly human rights and democracy. These two general categories are divided into subcategories. First, human rights are related to specific image schemas of freedom, women rights, dignity, a decent life and equality. Second, the general category "democracy" is linked to subcategories, mainly free and transparent elections, civil society, diverse political parties, free voters and less corruption. These subcategories, however, are in their turn divided into sub-schemas. Figure 3 illustrates how the concepts of freedom and women rights ignite sub-schemas in episodic memory: 


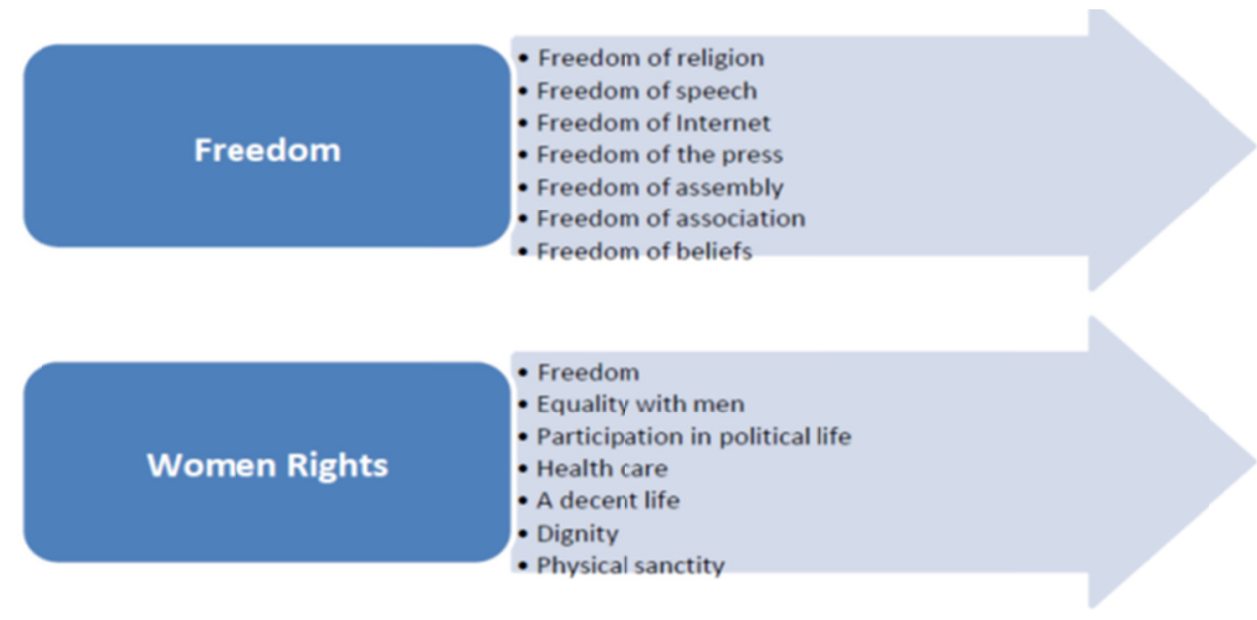

Figure 3. Diagrammatic representation of the organizational structures of freedom and women rights in Clinton's episodic memory

As one can notice in Figure 3, the mental representations of freedom and women rights are sub-divided into sub-categories. Freedom ignites sub-image schemas of freedom of religion, speech, Internet, press, assembly, association and beliefs. Similarly, the general mental model "women rights" triggers sub-image schemas, namely freedom, equality with men, participation in political life, health care, a decent life, dignity and physical sanctity. This enhances the idea that the speaker's episodic memory (Episodic memory stores personal experiences resulting from information processing in the STM) is organized in a hierarchical structure.

Apart from the hierarchical structure of mental models, one can acknowledge the prevalence of ICMs in Clinton's political discourse. First, prototypical image schemas about Tunisia, human rights and democracy are dominant in her discourse. For instance, Tunisia is portrayed as a "new democracy", like in "let me say Tunisia is a beautiful country, and you should come to visit, and you should support the new democratic Tunisia by being tourists here and put people back to work who are trying to build a new democracy" (Mar.17.11 Ap. B, p. 10). Tunisians, who took part in the revolution, are depicted as people who seek freedom and dignity. In addition, Tunisia is cognitively described as a beautiful country, and its location is mentally mapped as "strategic". Clinton emphasizes the importance of Tunisia's transition and enhances its role in influencing other countries in the Middle East and North Africa region. Subsequently, Clinton depicts positive mental frames or scripts, like in "And we think Tunisia is proceeding in the right direction, based on what we're seeing" (Feb.25.12\Ap. B, p. 23). To sum up, Tunisia is prototypically represented via positive mental models, frames or ICMs.

Second, ICMs are also clearly observed when Clinton refers to the USA. Indeed, the US is portrayed as a model that should be imitated, like in "And I think that anyone who believes in democracy should open their eyes to America" (Feb.25.12\Ap. B, p. 23). Clinton highlights the advantages of a democratic political system and calls for implementing it in countries that lack freedom and human rights. Freedom, human rights and democracy are mental models that prototypically represent American values. This is made clear in the following example: "the entire historical record shows we've been on the side of freedom, we've been on the side of human rights" (Feb.25.12\Ap. B, p. 23). As such, ICMs prototypically frame the USA as an ideal country that seeks to provide assistance and support to disadvantaged communities, like in "And it was exciting for us to remember all of that history, the support that the United States gave for Tunisian independence" (Mar.17.(3).12\Ap. B, p. 11). The USA is mentally mapped as the savior of the world that provides assistance and support to promote democracy and human rights.

However, it is important to note that mental models are ideologically biased in political discourse. Mental models are ideologically subjective because they represent events and entities from the perspective of an ideological group. For instance, in political discourse, mental models function as an interface between socially shared political cognitions and personal political beliefs. Consequently, biased or subjective political cognition affects political discourse, and hence communicates ideologically biased mental models, like in "I hope that what we will do is make it very clear that, $[\ldots]$ no one can claim to be representing the democratic will if their intention is to marginalize women" (July.1.11\App. B, p. 15). This example shows how mental models are ideological representations of the speaker's conceptual and perceptual worlds. Clinton's ideological bias in favor 
of women rights and women participation in political life is clear. People produce and understand discourse on the basis of socially shared attitudes and ideologies. In sum, Clinton's mental models in her political discourse are ideology-laden.

Finally, it is worth noting that information, pertaining to these text-based mental models, emanates from subjective mental models, general knowledge of the world as well as information about context. The textbase will, thus, involve only the information that is necessary and relevant in a given communicative act. Clinton has to activate and retrieve only the relevant mental models necessary to produce, process and comprehend discourse. Since discourse is controlled by the subjective interpretations of language users, one can deduce that discourse cannot be produced or understood unless people construct relevant subjective mental representations about it. In other words, discourse production and comprehension are based on decoding the implied, biased, mental models about context. Apart from text-based mental models, one has to examine general, context-free models in the selected corpus.

\subsubsection{General Context-Free Models: Ideologies and Knowledge}

The mental models built in Clinton's discourse are not only representations of actions, situations and events, but also positive or negative opinions and emotions associated with her personal experiences. More emphasis has to be on her views and perceptions of democracy and human rights in post-Ben Ali Tunisia. One has to unveil the link between linguistic and cognitive dimensions in Clinton's discourse. This is elaborated through the analysis of Clinton's personal ideologies and knowledge postulated via factive presupposition and epistemic modality. The aim is uncovering Clinton's ideological background and her personal political views and agendas regarding human rights and democracy. The focus has to be on Clinton's presupposed knowledge about these issues. More specifically, it is important to examine the structural organization of knowledge and the different image schemas and mental scripts activated in episodic memory to understand and produce political discourse.

To have a clearer idea about the ideological background of the speaker, one has to analyze the frequency of occurrence of words relating to the concept of ideology in the corpus. Figure 4 is an illustration of the frequency distribution of democracy-related rhetoric:

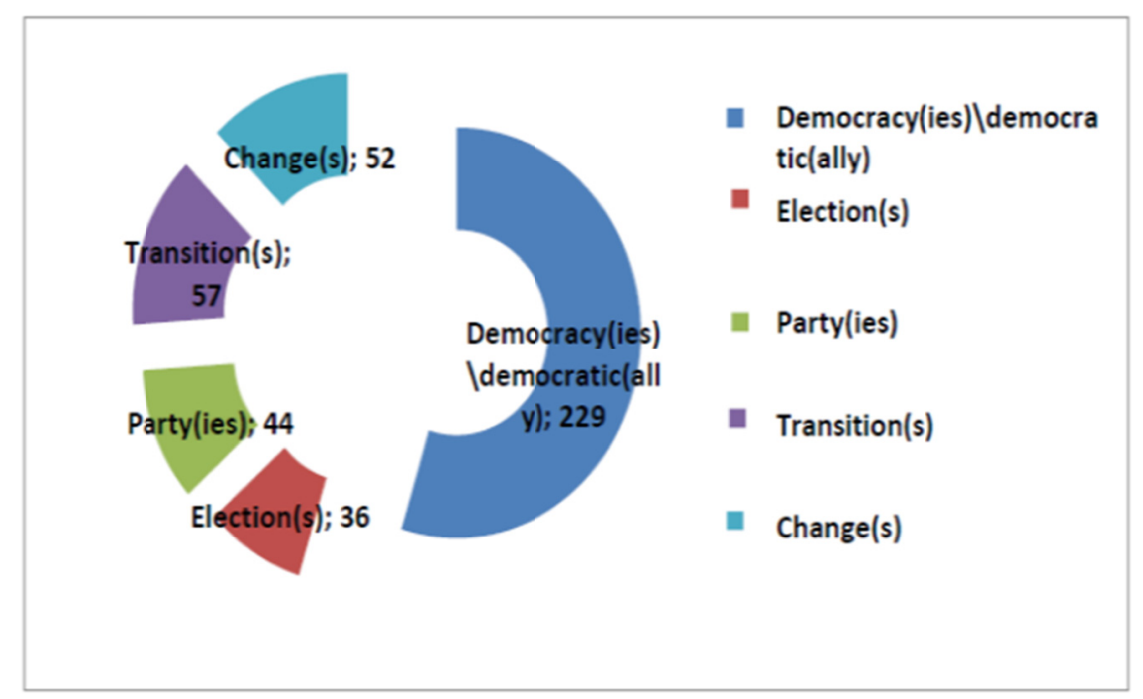

Figure 4. Diagrammatic representations of Clinton's rhetoric related to democracy in the corpus

Figure 4 explains how the rhetoric related to democracy is distributed in the whole corpus. One can notice the frequent occurrences of the word family "democracy" (229), including the singular noun "democracy" (124), the plural noun "democracies" (42), the adjective "democratic" (61) and the adverb "democratically" (2). One can also note the important use of the noun "transition(s)", which is used 57 times in its singular and plural forms. Similarly, the word "change(s)" is utilized 52 times in the corpus. The nouns "partylparties" and "election(s)" are also frequently used in the corpus with 44 and 36 occurrences successively. The recurrence of these words unveils the ideological dimension in Clinton's discourse. 
After analyzing the whole corpus in terms of knowledge manifested by the speaker, one can notice the use of two types of knowledge, mainly personal and social. To start with, Clinton's political discourse is a cluster of personal knowledge, based on personal mental models, or personal experiences about specific events. Clinton's personal knowledge about democracy and human rights is stored in LTM. These mental models are retrieved, activated and combined with new mental models about recent situations. Old and new image schemas influence each other to produce and comprehend discourse. Personal knowledge is private until it is shared by the speaker with other participants in the speech event. Once shared with recipients, knowledge is no longer personal, but social.

As for social knowledge, it is divided into group, institutional, cultural and universal knowledge. First, group knowledge is shared between democratic countries that share the same social and political values. Group members have similar epistemological backgrounds of general abstract knowledge about democracy and human rights. They may have the same experiences or the same sources of knowledge. Second, institutional or organizational knowledge is shared by the members of an institution or organization. In this context, one can give the following example that was produced in the UN Security Council "Democracies make the strongest, most capable partners. And we know that it takes a lot of hard work and oftentimes struggle." (Sep.26.12 \Ap. B, p. 30). Clinton's remarks are delivered at the UNSC regarding peace and security in the Middle East. The UN members share knowledge about the security situation in the region, and, therefore, $\mathrm{p}$ is institutional knowledge shared by participants in the UN.

Third, cultural knowledge can also be decoded in the corpus when Clinton tackles religious issues. For example, Clinton invokes cultural knowledge segments in "I mean, if you go to the United States, you see mosques everywhere, you see Muslim Americans everywhere. That's the fact." (Feb.25.12\Ap. B, p. 25). She defends the American cultural values, like religious tolerance and moderation. She tries to reject the rhetoric about Islamophobia in the US. Moreover, Clinton's personal knowledge about women seems to be a selection of sociocultural knowledge about women in her community, like in "You are obviously an intelligent young woman who's made your own choice, and I respect that. And I want every woman here to make her own choice, and we should all respect that as well" (Feb.25.12\App. B, p. 23). Clinton mentally evaluates the young woman as intelligent because she made her own choices. We can infer that Clinton respects free and independent women, who enjoy their rights. This draws a contrasting image with some Arab women, who are submissive, oppressed and deprived of their basic rights.

Finally, universal knowledge in Clinton's discourse is made clear when she discusses the issue of universal values or human rights. For instance, in "But at the same time, one must never forget universal values are vital to who we are and what we hope to see our world become." (Dec.6.12\App. B, p. 38), Clinton stresses the idea that human rights are not only American values but also universal and everyone's values. Clinton presupposes that these values are known to any individual and that they should be enjoyed by any human being worldwide. In short, knowledge in the corpus is both personal and social, including group, institutional, cultural and universal knowledge.

Knowledge in Clinton's discourse can also be classified as episodic and conceptuallsemantic. First, episodic knowledge is derived from past experiences and previous situations, like in "We are well aware of the challenges that come with these kinds of transitions" (Feb.28'.11 \App. B, p. 2). Hence, Clinton's previous experience as part of a democratic system makes her conscious of the challenges that come with democratic transitions. Second, semantic, or conceptual knowledge is inferred from generalization, abstraction and de-contextualization. An example of generalized knowledge is the following: "[...] while remembering that human rights are at the center of some of the most significant challenges to global security and stability and therefore to our national interests" (Dec.6.12\App. B, p. 38). In sum, knowledge in Clinton's discourse is both episodic and conceptual.

To sum up, it has been shown that knowledge in Clinton's political discourse is personal, social, cultural, national and universal. It is ideologically biased and politically oriented. Like beliefs, knowledge may be relative and subjective since it represents reality from the speaker's angle or perspective. Finally, knowledge consists of fragments that are structural and hierarchical. As for the social dimension of the speaker's cognition, the analysis of personal cognition in Clinton's political remarks on democracy and human rights in Tunisia in post-Ben Ali period has demonstrated that Clinton's personal values, attitudes, ideology, and knowledge are selections of socially shared mental representations of her epistemic community, mainly the USA, and democratic communities in general. 


\section{Discussion}

At this level, one has to focus on the most important research findings and relate them to the research questions in an attempt to reach the objectives of the present study. To start with, the lexical features that trigger factive presupposition and epistemic modality in Hillary Clinton's discourse, mainly factive and emotive verbs, factive noun phrases, mental state verbs, epistemic adverbs and adjectives, have been sorted out. The aim is demystifying presupposed knowledge regarding human rights and democracy in the Arab World in Tunisia in the aftermath of Ben Ali's regime collapse in January 2011.

"Think" is a predicate that performs a mental act that endorses a judgment, an evaluation, an assessment or an opinion. Such a judgment reveals the perspective or point of view of the speaker. It is the mirror that reflects the speaker's perception of the real as well as fictitious worlds. It is a translation of how the user understands and interprets events and entities around her. It has been noticed while analyzing the corpus that "think" is a mental state verb that sells personal, subjective opinions as objective, reliable judgments. Speakers may serve specific agendas and ideologies, and hence encode their opinions and attitudes towards certain political parties, or social trends in a form of objective views based on evidence. They may also give the illusion that these opinions are mutually shared by the hearers, or the epistemic community to urge receivers to accept them without checking their validity. Such fake objectivity may deter recipients from challenging the truth value of such judgments. They take them as taken for granted or presupposed truths, hence the speaker's and hearers' epistemological worlds converge. However, some recipients may doubt the truth conditionality of such thoughts, and interrupt discourse to correct the speaker's information, and hence the two epistemic worlds diverge.

"Think" foregrounds information and explicitly reveals the propositional content of the utterance. "Think" expresses the attitude of the speaker clearly, leaving no doubts on the part of the hearer. More specifically, it is a direct and subjective way to translate personal as well as group thoughts and opinions about certain issues. In other words, it designates a great deal of speaker involvement and reflects a strong engagement to the truth conditionality of a given proposition. Such strong personal involvement unveils the speaker's perception of events, entities and issues and her mental and epistemological state. In other words, the use of the mental state verb "think" reveals the cognitive mechanisms used to understand issues in the world. In sum, the mental state predicate "think" is subjectivity-laden since it portrays the speaker's personal thoughts and her own views.

Unlike "think", which expresses attitudes, hence the speaker's ideology, the factive verb "know" reflects knowledge about the real world. It reflects what an individual knows about the physical world, hence personal knowledge that stems from personal experiences. The source of such knowledge must be reliable, and this explains why Clinton, sometimes, opts for evidential verbs, like "see", "tell", "hear" and "say". The predicate "know" translates what can be seen in the physical, real world without any evaluation on the part of the speaker. It is an objective description of reality or reliable transfer of information from source to target.

Since "know" is a primary verb that expresses the speaker's knowledge, it is used to claim the objectivity and reliability of information. It is also a factive verb that takes a complement clause whose truth conditionality is clearly presupposed by the addresser. Indeed, what is presupposed in $\mathrm{p}$ ( $\mathrm{p}$ stands for proposition) is presented as taken for granted. The proposition is introduced as previous knowledge that is personal or shared by an epistemic community. Such past knowledge seems to be unchallengeable and irrefutable by discourse participants since it is not the speaker's personal point of view or a biased attitude towards events. The use of the factive predicate "know" means that the proposition is based on evidence or a reliable source. As such, knowledge is not a matter of doubt or controversy because it has to be shared and accepted by all group members.

"Know" is a presupposition trigger, and, therefore, factuality is expressed in the complement clause in an implicit or indirect way. The proposition in that-clause is classified as backgrounded knowledge. Presupposed, backgrounded information cannot be rejected, and hence recipients just accept it as shared knowledge. Consequently, factive presupposition can serve certain group interests and promote the ideologies of certain communities. For instance, presupposed knowledge may be used by manipulators to distort truths and misrepresent other groups or ideologies. In this regard, one can note that the use of "think" (51 items) and "know" (51 items) in the corpus shows that Clinton's discourse is based on a dichotomy, mainly opinionslideologies and knowledge. Indeed, "think" expresses the point of view of the speaker in an explicit and direct way, whereas "know" encodes the speaker's presupposed knowledge. Presuppositions are taken for granted by Clinton, or she pretends taking them for granted to serve ideological purposes. Such implicit, presupposed information is represented in ideologically biased mental models. For these reasons, presuppositions can be deceptive and manipulative. 
"Know" is a typical factive verb that triggers factive presupposition, while "think" is a typical verb that signals epistemic modality. A presupposition is always restricted to non-asserted true propositions, while epistemic modality asserts the propositional content of utterances. In whole, the features that embed presupposed, factive information are 94 items, compared to 104 features that describe the epistemological or knowledge state of the speaker. Subsequently, both factive presupposition and epistemic modality nearly evenly uncover Clinton's mental state and her perception of the world. In other words, epistemic presupposition and epistemic modality reveal both the unstated and stated knowledge and attitudes in the corpus. Epistemic presupposition deals with what is unstated in the corpus, while epistemic modality focuses on what is stated in Clinton's discourse. For instance, propositions introduced by "know" pertain to non-asserted, taken for granted knowledge, whereas propositions stated after "certainly" are asserted beliefs or knowledge. "Remind" is, however, between presupposing and asserting and pertains to the shared knowledge of a group.

Another objective of the present research is investigating how mental models influence discourse production and comprehension. In this regard, it has been confirmed that information about events, concepts, entities and their related features is stored in the episodic memory. Information is interpreted as representations, and, thus, people construct models about concepts, like elections, dictators, universal values, etc. People also construct models about context, like participants' interests, objectives, norms and identity that can help decode the meaning of discourse, hence context models. It has been shown that mental models are knowledge fragments or cognitive image schemas that represent human rights as one of the basic prerogatives to democracy. Democracy is also mentally framed as the most suitable political system that meets the aspirations of Tunisians. More specifically, mental models are knowledge scripts that are stored, retrieved and activated to comprehend discourse. These mental models are socially and culturally variable because they depend on the attitudes, values, ideologies and knowledge set of the interpreter.

After identifying the different types of knowledge found in the corpus, one has to discuss the main results obtained from the analysis of knowledge within the socio-cognitive framework. Knowledge is conceptualized as mental representations, stored in LTM, but activated and used in STM. Knowledge takes the form of frames, scripts or schemas that help the speaker, in this case, Hillary Clinton, to understand and produce discourse. Discourse comprehension occurs via building mental models by retrieving and activating relevant knowledge fragments in episodic memory. Clinton selects the knowledge fragments that should be implicitly expressed, and the knowledge instantiations that should be explicitly stated in discourse. Depending on context, Clinton opts for implied presupposed knowledge or apparent explicit knowledge. This also depends on the speaker's k-device that helps to guess how much knowledge is already shared and how much knowledge needs to be shared with recipients at time ${ }^{\mathrm{t}}$ or speaking time.

Presupposed knowledge is inferred from Clinton's uses of factive presupposition triggers, mainly factive predicates, emotive verbs and factive noun phrases. As stated in previous sub-sections, presupposed knowledge is implicit, hidden and indirectly expressed. Presupposed knowledge is taken for granted and assumed to be true by Clinton and discourse recipients. In other words, it has to be known and accepted by participants so that other propositions can be meaningful. Though presupposed knowledge is known by the epistemic community, Clinton, sometimes, reminds the addressees of already known information, like in "And it was exciting for us to remember all of that history, the support that the United States gave for Tunisian independence" (Mar.17'.11 $\backslash$ App. $\mathrm{B}, \mathrm{p}$ 11). Clinton is aware of what the recipients already know because she adjusts her discourse and includes only the relevant knowledge slots for the social situations or communicative events she takes part in.

However, presupposed knowledge is not always assumed to be known by the hearers. The speaker may imply presupposed knowledge to indirectly express what is not known by the recipients before the ongoing speech event. In this context, the speaker should be aware of what the recipients want to know because it is relevant or interesting for them, like in "[...] while remembering that human rights are at the center of some of the most significant challenges to global security and stability and therefore to our national interests" (Dec.6.12\App. B, p 38). In this utterance, Clinton highlights the importance of human rights for international security and stability. In spite of the use of the factive predicate "remember", which triggers factive presupposition, the proposition may not be shared or accepted by recipients.

From a semantic perspective, discourse is the tip of the iceberg since only some propositions are explicitly expressed in discourse, while the remaining propositions are presupposed, hidden and indirectly stated. In the present research, Clinton's remarks regarding the Tunisian revolution are factivity-laden because, as it has been shown, most of the utterances that include factive presupposition triggers or epistemic modals are presented as true facts. The speaker demonstrates high degrees of personal involvement to the truth conditionality of her propositions. Discursively, knowledge is given as undisputed, unchallengeable facts since it is stated by a 
competent member of the epistemic community. Indeed, Clinton is the US Secretary of State at the time of discourse production, and hence most hearers seem to accept what is presupposed as factual knowledge in her discourse.

One can note that presupposed knowledge uncovers the background knowledge of the speaker, and demystifies her ideological background. Although knowledge is defined in epistemology as justified true beliefs, it may embed beliefs and attitudes. For instance, in the following example, Clinton presents the proposition as factive knowledge: "So I think we have demonstrated that we support democracy, and we support it where it is occurring." (Feb.25.12\Ap. B, p. 23). This utterance unveils the background knowledge of the speaker. The proposition is also shared within the American and pro-democratic communities in the USA. Consequently, what is expressed is a belief that is shared by the same group members to the point that it becomes common-ground knowledge or a fact. It can also be widely shared and presupposed in larger epistemic communities, in this case, democratic nations worldwide, hence universal, presupposed knowledge.

Such background knowledge is basically ideological. The group ideologies, found in Clinton's political discourse, can be classified as democrat, humanist and feminist ideologies. First, Clinton's socially shared knowledge about democracy is ideology-laden, like in "And we are investing in innovation, because we know that governments on the other side of this fight are constantly improving their methods of oppression" (Dec.6.12\Ap. B, p. 41). In this utterance, Clinton is ideologically biased against non- democratic groups or nations. Her knowledge is determined on the basis of the k-device or ideological parameters of her group, its goals and interests. As such, Clinton's repertoire reveals her ideological background as a democrat.

Second, the humanist ideology is clear in the following example: "A party that is a religious-based party has to recognize the freedom of religion, association, assembly, and speech" (Feb.25.12\Ap. B, p. 23). Clinton shows her ideological background as a humanist, who defends the rights and freedoms of people. These values are perceived, interpreted and represented on the basis of group convenience and common ground. Knowledge is, therefore, relative to the beliefs and attitudes of an epistemic community that shares the same beliefs, values and norms. In short, Clinton's ideology as a humanist is obvious in her discourse.

Third, Clinton's discourse reflects a feminist orientation. The feminist ideological background is clear in this example: “And you can't be a democracy if you don't listen to half the population and you don't respect the role that women have and give women the same opportunity to be in business, politics, run for office, everything else. So I think it's very promising" (Mar.17.11\Ap. B, p. 10). Beliefs are relative depending on the person's perspective, culture, background and identity. The proposition is considered as knowledge according to human rights' activists and western societies. However, it may be perceived as false beliefs, for instance, by Muslim communities, who adopt Islamic values that may not coincide with western values and norms.

Whether she is a democrat, humanist or feminist, Clinton presents her beliefs as objective, indisputable facts. Her beliefs act as the epistemic common ground of democrats, human rights' activists and feminists worldwide. These values are accepted, approved and adopted by the members of the same epistemic community. As such, ideologies determine the social representations of the group and determine knowledge. Since knowledge and ideology are interrelated, both of them affect discourse production and comprehension. Indeed, Clinton's discourse is tainted with ideological assumptions or manifestations of her attitudes and norms. In sum, Clinton's remarks regarding the Tunisian revolution are basically ideological but presented as factive presuppositions.

With regard to knowledge structure, it is schematically represented as "scripts", or "slots" about stereotypical events or entities. Knowledge is organized as schemas or certain networks that are structured in terms of categorical relations. Knowledge consists of cognitive representations, mental models, or a mental mapping of certain concepts or events. Since a hierarchical structure has been noticed while analyzing mental models about democracy and human rights in previous sub-sections, the same applies to knowledge in general. Indeed, knowledge, as a mental construct, is schematically represented in different frames that take into account the typical features of the world units that surround a given concept.

While analyzing frames in the corpus, one can notice that knowledge is saved in memory as several related frames. For instance, "democracy" frame is characterized by specific prototypical features. For example, in "[...] and at the same time reminding Egyptians and Libyans and Tunisians and others that democracy is not one election one time" (Feb.26.12\Ap. B, p. 26), one can construct frames and sub-frames. The general frame is democracy, and the sub-frames that may be formed are elections, political parties, plurality and voters. These sub-frames or features encode the prototypes that typically represent the category "democracy". Knowledge is the interrelations between frames that are built upon these categories or prototypical features. 
These PROTOTYPES or prototypical knowledge frames influence how Clinton perceives the world. For instance, Clinton's perception of women rights is based on frames and sub-frames. The typical features of women rights are equality with men, freedom, dignity, physical sanctity, health, education etc. Such set of knowledge slots determine Clinton's construal of women situation in her epistemic world and her attitude towards women. As shown in the previous section, the organizational structure of these mental frames is hierarchical, ranging from general to specific mental categories. These frames can also be classified in terms of dominance from the most dominant to the least dominant features in Clinton's discourse. The most dominant frames are the "DEMOCRACY-FRAME" and "HUMAN RIGHTS-FRAME". These general frames can be divided into sub-frames, such as "women rights sub-frame", "religious freedom sub-frame" and "free elections sub-frame". This leads to a network of epistemic units that are made of interrelated frames and sub-frames. Inspired by Aitchison's (2012, p. 228) lexical network, figure 5 illustrates how knowledge frames are organized in the corpus:

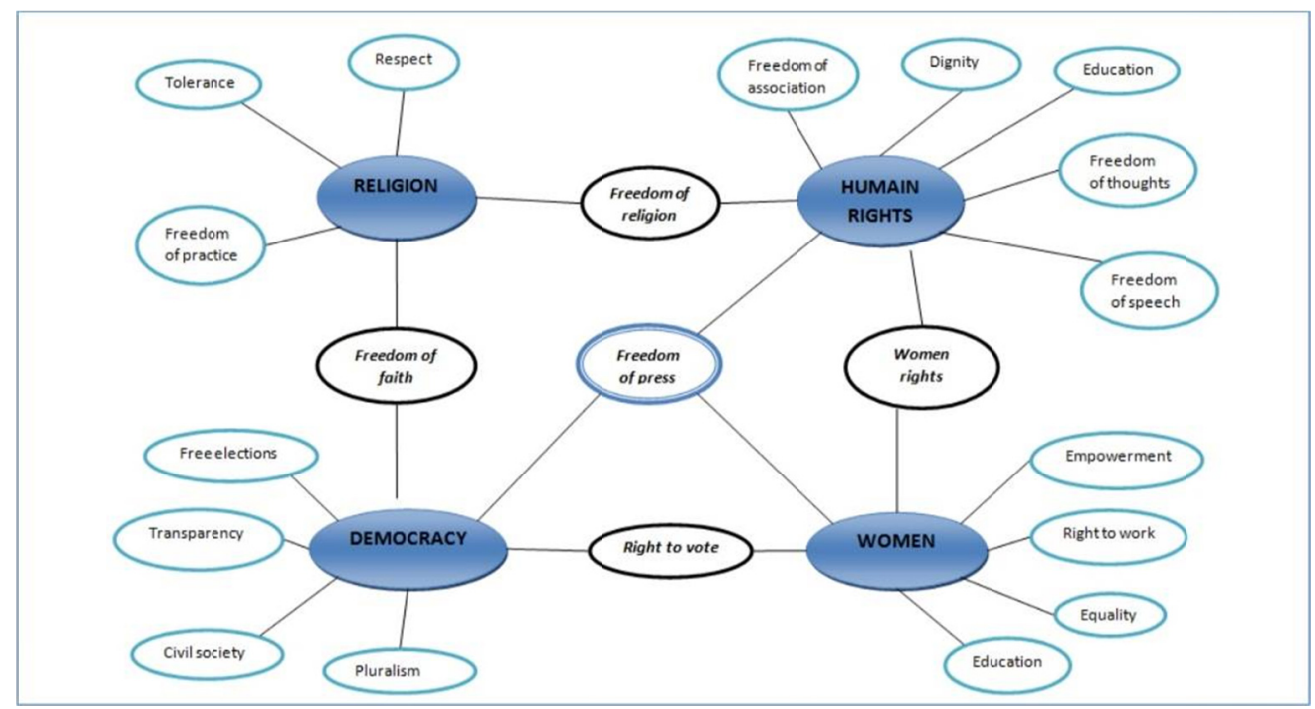

Figure 5. Networks of knowledge frames in the corpus

Words, like "democracy", "human rights", "religion" and "women", build lexical towns in the form of a mental network. Every lexical town in figure 5 involves several clumps of words that are strongly interrelated. These words have other weaker relations, semantic connections or common aspects with other groups. As such, the mental lexicon has strong and weak bonds with other words depending on the topic.

Since one of the objectives of the present research is studying the ideological knowledge backgrounds implied in Clinton's discourse, it has been demonstrated that ideologies determine Clinton's beliefs, attitudes and views about the world. Indeed, ideologies affect the socially shared representations about human rights and democracy with respect to Tunisia and Arab Revolutions. It has also been shown that knowledge is ideologically biased and depends on the ideological parameters of the group, like the group goals, norms and interests. In fact, the epistemic common-ground beliefs are presented as indisputable facts and unchallengeable truths. Though knowledge is not always ideological, the knowledge scripts or frames, derived from fragments of old experiences, and both the real and conceptual worlds, are, sometimes, cognitively and socially relative. Similarly, it has been shown that knowledge, whether general or specific, episodic or conceptual, personal or social, cultural, institutional, national or global, may be ideologically tainted to promote the speaker's agenda and her epistemic community's values, attitudes and ideologies discursively, cognitively and socially.

One can, therefore, recapitulate that factive knowledge is manifested in Clinton's political discourse via mental models, cognitive frames, image schemas and knowledge scripts, stored in LTM and activated in episodic memory, or STM. One can also state that such cognitive frames or knowledge fragments are schematically structured and organized from general to specific categories and sub-categories. General categories represent human rights and democracy, while sub-categories represent women rights, freedom, religious freedom, free elections etc. Clinton uses factive presupposition triggers to background information. She also opts for epistemic modality to reach the same purpose. However, mental state verbs, especially "think", foreground information and 
express opinions and attitudes, but not knowledge. In sum, Clinton tends to present personal opinions and attitudes as presupposed, taken for granted, factive truths.

At this level, one has to show how mental models, personal and social ideologies and knowledge unmask Clinton's perceptual as well as conceptual worlds, at the cognitive level. First, it has been found out that mental models and sub-models are evaluative and subjective interpretations of social situations. It has also been demonstrated that these mental frames are fragments of past experiences and previous knowledge, hence what is already stored in our memories about the real, perceptual world as well as what we internalize from the abstract, conceptual world. The retrieval and activation of such cognitive frames facilitate discourse production and understanding. Decoding these mental representations in discourse uncovers the speaker's cognitive frames and the kind of mental models she stores via discourse lexical features.

Second, it has been revealed that the different ideological assumptions or traces found in the corpus uncover the ideological background of Hillary Clinton, her political orientation as well as her government's agendas in North Africa and the Middle East. These ideological assumptions are reflections of Clinton's perceptual world and her epistemological state of mind as a democrat, humanist, pacifist and feminist. Knowledge also mirrors the speaker's thoughts and facts. While analyzing Clinton's political discourse, the focus has been on back-grounded, presupposed knowledge as well as fore-grounded, explicit knowledge of the discourse producer. Both types of knowledge reflect the conceptual world of the speaker with respect to human rights and democracy. In sum, ideology and knowledge translate and portray the perceptual and conceptual worlds of the speaker and describe her mental state of affairs.

As the current research studies factive vs. ideological knowledge in Clinton's political discourse, it is important to highlight the idea that knowledge in Clinton's discourse ranges from the simplest perceptual contact with the physical world to the most complicated cognitive effort while evaluating concepts, such as ICMs, mental spaces, cognitive representations etc. The k-device is crucial for the control of many important aspects of discourse, such as what information is explicitly expressed and asserted, what information has to be reminded and what information is presupposed. Clinton presents knowledge as intellectually virtuous because it reflects reality as well as the factual world. However, she imposes her beliefs and assumptions as generally accepted knowledge. By imposing one's beliefs as true, presupposed knowledge, the speaker marginalizes large audience segments by presupposing knowledge that is not generally known or that is not accepted by other communities. Consequently, Clinton can sell her views-disguised-as-truths by giving the illusion that personal knowledge, most of the time ideologically-tainted, is shared by all discourse participants.

It is also important to note that the distinction between knowledge and belief is scalar. Like knowledge, beliefs are organized in terms of higher-order and lower-order beliefs. Beliefs are represented by Clinton as networks of belief-clusters that are structured by various schemata. Generally, subjective propositions are based on the speaker's beliefs, while objective propositions are based on the speaker's knowledge. Propositions, based on the speaker's beliefs, are evaluative judgments. This presupposes that propositions, based on the speaker's knowledge, are factive segments of information. Subsequently, ideologies monitor evaluative beliefs but not factive knowledge. Ideologies determine people's beliefs about the world and control the way the epistemic community evaluates knowledge. Political knowledge is mostly group knowledge that is considered by opposing groups as mere political opinions.

Finally, one has to emphasize the idea that CDA is discourse analysis with attitude. It takes an explicit sociopolitical stance by spelling out points of view. It portrays the world and criticizes social and political issues. Likewise, it shows the conceptual outcome of ideological language choices. Clinton's discourse interprets conditions, problems and events in favor of the elites' interest, in this case the US interests and agendas in the MENA region. The discourse of the marginalized groups is, however, considered a threat to the ideological interests and propaganda efforts of the elite. CDA, hence, analyses the socially or morally illegitimate control of minds, especially when emitters control the minds of recipients in a self-serving way.

\section{Conclusions}

To conclude, Clinton's discourse is based on a dichotomy, mainly implicit vs. explicit knowledge, indirect vs. direct meanings, back-grounded vs. fore-grounded ideas and presupposed vs. exposed knowledge. Both factive presupposition lexis and epistemic modals signal the speaker's epistemological knowledge state. This demystifies Clinton's perceptual and conceptual worlds. In this regard, one can confirm that Clinton plays a language game by apparently presenting knowledge as factive to manipulate recipients and promote the agenda of her government. Her discourse is ideologically biased since she boosts the American ideals and democratic principles in Arab countries. At the discourse level, factive presupposition and epistemic modality mirror the 
speaker's backgrounded vs. foregrounded knowledge, her perception of Tunisia's revolution and her conception of human rights and democracy. At the cognitive level, mental models, as well as the personal and social cognition of Hillary Clinton demonstrate that knowledge is ideological, but disguised as factive in her discourse.

The main contribution of the current research is that it provides needed evidence on the link between factive presupposition and epistemic modality and their role in constructing knowledge and building the perceptual and conceptual worlds of the speaker. The connection between presupposition and modality has been made explicit by showing evidence on the epistemic mental state of the speaker and how she constructs factive knowledge and ideological assumptions about entities, concepts, events and the world. The mental processes that govern Clinton's discourse production and comprehension have been practically explained via the analysis of presupposition and modality. More particularly, the epistemological dimensions of factive presupposition and epistemic modality have been analyzed within van Dijk's (1995a) discourse-cognition-society paradigm. The focus has been on the mental modeling and cognitive mechanisms that construct ICMs, mental frames, image schemas and prototypical representations about Tunisia's democratic experience and its unique emancipatory revolution in 2011-2012.

The limitation of the present study is that focus has only been on Hillary Clinton as discourse emitter. Although presupposed knowledge in Clinton's discourse is presented as irrefutable and inescapable, active and intelligent recipients may not accept it as shared, presupposed knowledge. They may doubt its truth value and reject it because of its incompatibility with their epistemic worlds. Since there is no idealized knower, people may not accept whatever the speaker says. Skepticism can be stimulated by incompatibility between what is said and the real world, or between what is said and the abstract knowledge of the addressees. As such, what is presupposed may diverge from what is mutually known or believed to be true. In short, eliminating or excluding other discourse participants limits the scope of analyzing political discourse.

\section{References}

Aitchison, J. (2012). Words in the Mind: An Introduction to the Mental Lexicon. Oxford, UK: Wiley-Blackwell.

Beaugrande, R. (1991). Linguistic Theory: The Discourse of Fundamental Works. London, UK: Longman.

Jaworski, A., \& Coupland, N. (1999). The Discourse Reader (pp. 1-42). London, UK: Routledge.

Karttunen, L. (1972). Possible and Must. In J. P. Kimball (Ed.), Syntax and Semantics (vol. 1, pp. 1-20). New York, NY: Academic Press.

Karttunen, L. (1973). Presuppositions of Compound Sentences. Linguistic Inquiry, 4(2), 169-193.

Kratzer, A. (1981). The Notional Category of Modality. In H. J. Eikmeyer \& H. Rieser (Eds.), Worlds, Words, and Contexts (pp. 38-74). Berlin: De Gruyter. https://doi.org/10.1515/9783110842524-004

Kratzer, A. (1991). Modality. In A. von Stechow \& D. Wunderlich (Eds.), Semantics: An International Handbook of Contemporary Research (pp. 639-650). Berlin: De Gruyter.

Levinson, S. C. (1983). Presupposition. In S. C. Levinson (Ed.), Pragmatics (pp. 167-225). Cambridge, MA: Cambridge University Press. https://doi.org/10.1017/CBO9780511813313.007

Lyons, J. (1977). Semantics. Cambridge: Cambridge University Press.

Perkins, M. (1983). Modal Expressions in English. London, UK: Frances Pinter.

van Dijk, T. (1983). The Cognitive Representation of Attitudes and Prejudice. Forum Linguisticum, 7(3), 189-204.

van Dijk, T. (1990). Social Cognition and Discourse. In H. Giles \& W. P. Robinson (Eds.), Handbook of Language and Social Psychology (pp. 163-183). Chichester: John Wiley \& Sons.

van Dijk, T. (1995a). Discourse Analysis as Ideology Analysis. In C. Schäffner \& A. I. Wenden (Eds.), Language and Peace (pp. 17-33). Amsterdam: Harwood Academic Publishers.

van Dijk, T. (1995b). Discourse Semantics and Ideology. Discourse and Society, 6(2), 243-289. https://doi.org/10.1177/0957926595006002006

van Dijk, T. (1995c). Ideological Discourse Analysis. In E. Ventola \& A. Solin (Eds.), Interdisciplinary Approaches to Discourse Analysis (Vol. 4, pp. 135-161). New Courant: English Department, University of Helsinki.

van Dijk, T. (1998). Ideology: A Multidisciplinary Approach. London, UK: Sage. 
van Dijk, T. (1999). Context Models in Discourse Processing. In H. van Oostendorp \& S. R. Goldman (Eds.), The Construction of Mental Representations during Reading (pp. 123-148). Hillsdale, NJ: Erlbaum.

van Dijk, T. (2000). Ideology and Discourse: A Multidisciplinary Introduction. English Version of an Internet Course for the University of Oberta de Catalunya. Barcelona: Pompeu Fabra University. Retrieved from http://www.discourses.org/UnpublishedArticles/Ideology\%20and\%20discourse.pdf

van Dijk, T. (2001). Discourse, Ideology and Context. Folia Linguistica, 35(1-2), 11-40. https://doi.org/10.1515/flin.2001.35.1-2.11

van Dijk, T. (2003a). Knowledge in Parliamentary Debates. Journal of Language and Politics, 2(1), 93-129. https://doi.org/10.1075/jlp.2.1.06dij

van Dijk, T. (2003b). Specialized Discourse and Knowledge: A Case Study of the Discourse of Modern Genetics. In E. M. Morato, A. C. Bentes, \& M. L. Cunha Lima (Eds.), Homenagem an Ingedore Koch. Cadernos de Estudos Lingüisticos (vol. 44, pp. 21-55). Campinas, Brasil: Unicamp.

van Dijk, T. (2003c). The Discourse-Knowledge Interface. In G. Weiss \& R. Wodak (Eds.), Critical Discourse Analysis. Theory and Interdisciplinarity (pp. 85-109). Houndsmills, UK: Palgrave-MacMillan.

van Dijk, T. (2004a). Discourse, Knowledge and Ideology: Reformulating Old Questions and Proposing Some New Solutions. In J. Neff-van Aertselaer, T. van Dijk, U. Ammon, R. Dirven, \& M. Putz (Eds.), Communicating Ideologies. Multidisciplinary Perspectives on Language, Discourse and Social Practice (pp. 5-38). Oxford: Peter Lang.

van Dijk, T. (2004b). Knowledge and News. Revista Canaria de Estudios Ingleses, 49, 71-86.

van Dijk, T. (2005). Contextual Knowledge Management in Discourse Production: a CDA Perspective. In R. Wodak \& P. Chilton (Eds.), A New Agenda in (Critical) Discourse Analysis (pp. 71-100). Amsterdam: Benjamins. https://doi.org/10.1075/dapsac.13.07dij

van Dijk, T. (2006). Politics, Ideology and Discourse. Elsevier Encyclopedia of Language and Linguistics. In R. Wodak (Ed.), Politics and Language (pp. 728-740). London, UK: Elsevier.

van Dijk, T. (2009). Critical Discourse Studies: A Socio-cognitive Approach. In R. Wodak \& M. Meyer (Eds.), Methods of Critical Discourse Analysis (pp. 62-85). London, UK: Sage.

van Dijk, T. (2012). Discourse and Knowledge. In G. P. Gee \& M. Handford (Eds.), Handbook of Discourse Analysis (pp. 587-603). London, UK: Routledge.

Yule, G. (1996). Pragmatics. Oxford, UK: Oxford University Press.

\section{Copyrights}

Copyright for this article is retained by the author, with first publication rights granted to the journal.

This is an open-access article distributed under the terms and conditions of the Creative Commons Attribution license (http://creativecommons.org/licenses/by/4.0/). 